Amit Agarwal, Benjamin Kicköfer

\title{
The correlation of externalities in marginal cost pricing: lessons learned from a real- world case study
}

Journal article | Accepted manuscript (Postprint)

This version is available at https://doi.org/10.14279/depositonce-10067

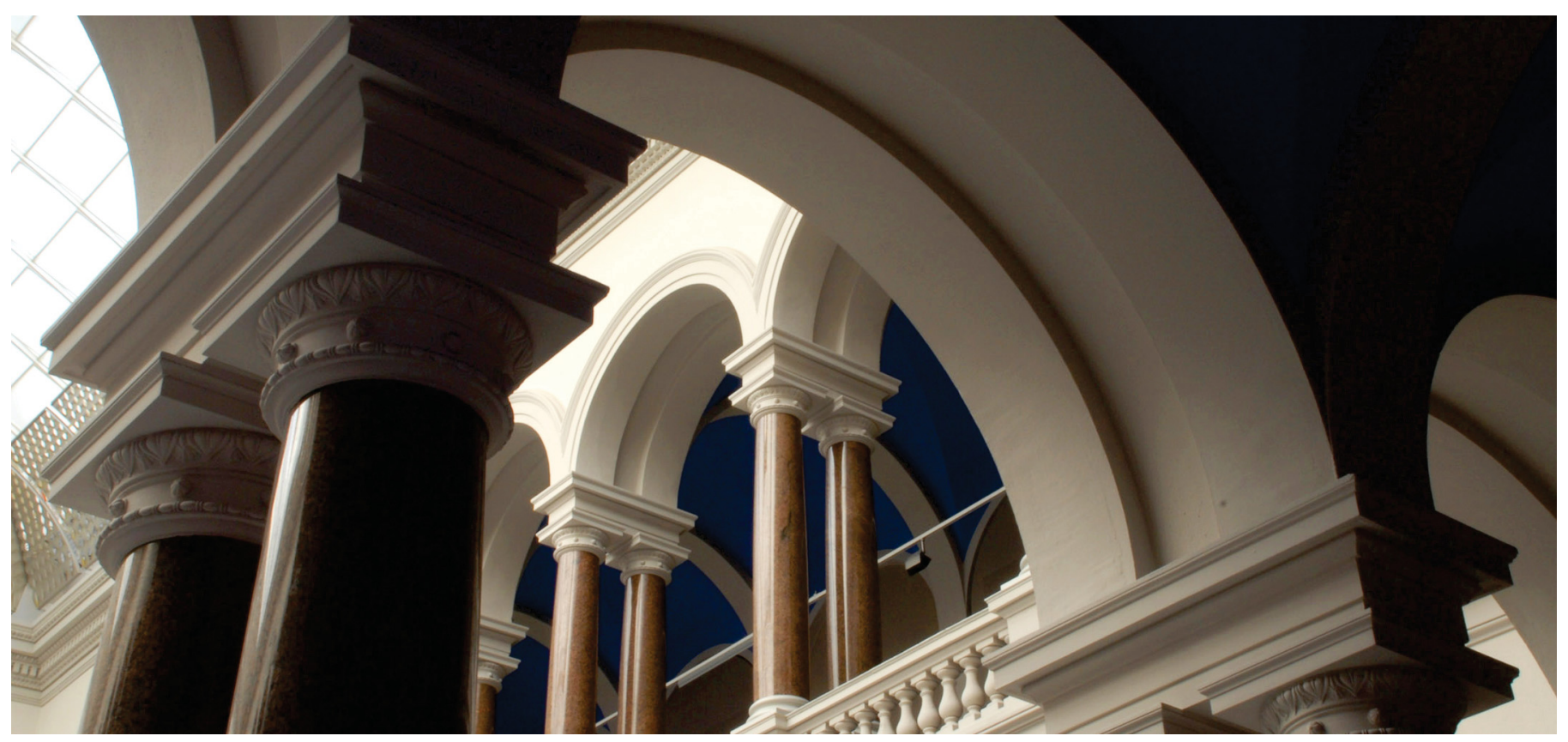

Agarwal, A., \& Kickhöfer, B. (2016). The correlation of externalities in marginal cost pricing: lessons learned from a real-world case study. Transportation, 45(3), 849-873. https://doi.org/10.1007/ s11116-016-9753-z 


\title{
The correlation of externalities in marginal cost pricing: Lessons learned from a real-world case study
}

\author{
Amit Agarwal • Benjamin Kickhöfer
}

Received: date / Accepted: date

Preferred citation style: Agarwal, A. and B. Kickhöfer (2016). "The correlation of externalities in marginal cost pricing: Lessons learned from a real-world case study". In: Transportation. DOI: 10.1007/s11116-016-9753-z. The final publication is available at http://link.springer.com.

\begin{abstract}
Negative externalities cause inefficiencies in the allocation of capacities and resources in a transport system. Marginal social cost pricing allows to correct for these inefficiencies in a simulation environment and to derive real-world policy recommendations. In this context, it has been shown for analytical models considering more than one externality, that the correlation between the externalities needs to be taken into account. Typically, in order to avoid overpricing, this is performed by introducing correction factors which capture the correlation effect. However, the correlation structure between, say, emission and congestion externalities changes for every congested facility over time of day. This makes it close to impossible to calculate the factors analytically for large-scale systems. Hence, this paper presents a simulation-based approach to calculate and internalize the correct dynamic price levels for both externalities simultaneously. For a real-world case study, it is shown that the iterative calculation of prices based on cost estimates from the literature allows to identify the amplitude of the correlation between the two externalities under consideration: For the urban travelers of the case study, emission toll

A. Agarwal

Transportation System Planning and Telematics

Technische Universität Berlin, Sekr. SG 12, Salzufer 17-19, 10587 Berlin, Germany

E-mail: amit.agarwal@campus.tu-berlin.de

B. Kickhöfer

Institute of Transport Research

German Aerospace Center (DLR), Rutherfordstraße 2, 12489 Berlin, Germany

E-mail: benjamin.kickhoefer@dlr.de
\end{abstract}


levels - without pricing congestion - turn out to be $4.0 \%$ too high in peak hours and $2.8 \%$ too high in off-peak hours. In contrary, congestion toll levels - without pricing emissions - are overestimated by $3.0 \%$ in peak hours and by $7.2 \%$ in off-peak hours. With a joint pricing policy of both externalities, the paper shows that the approach is capable to determine the amplitude of the necessary correction factors for large-scale systems. It also provides the corrected average toll levels per vehicle kilometer for peak and off-peak hours for the case study under consideration: Again, for urban travelers, the correct price level for emission and congestion externalities amounts approximately to 38 EURct/ $\mathrm{km}$ in peak hours and to $30 \mathrm{EURct} / \mathrm{km}$ in off-peak hours. These toll levels can be used to derive real-world pricing schemes. Finally, the economic assessment indicators for the joint pricing policy provided in the paper allow to compare other policies to this benchmark state of the transport system.

Keywords Air Pollution · Congestion · Vehicle Emissions · Road Pricing • Combined Pricing $\cdot$ Internalization

\section{Introduction}

Improvements in the transport sector yield positive externalities such as increased accessibilities, increased land values and agglomeration benefits. On the contrary, they also impose negative externalities ${ }^{1}$ on society. These include accidents, congestion, damages to the environment and human health (see, e.g., Weinreich et al 1998; Maibach et al 2008). The expected increase in mobility needs in densely populated areas, mainly resulting from urbanization processes, is likely to increase the negative externalities. The presence of negative externalities is known to result in inefficiencies unless the underlying external costs are reflected in the market prices for mobility, i.e. considered in people's mobility decisions. Potential efficiency gains amount to a considerable share of a country's GDP (Gross Domestic Product): For example, the total external costs by motorized traffic in Beijing is estimated to range between $7.5 \%$ and $15 \%$ of the city's GDP (Creutzig and He 2009). The total external costs in the EU-27 plus Norway and Switzerland is estimated to amount to approximately 5 to $6 \%$ of the union's GDP (van Essen et al 2011).

One option in order to reduce the efficiency loss is to aim for behavioral changes of people. From the economic literature, it is known that internalizing external effects by a tax can change behavior and, thus, increase welfare for society (Pigou 1920). However, only some real-world policies have been implemented in the last decades. Congestion pricing schemes have been introduced in Singapore, London, Stockholm (Eliasson et al 2009), and Gothenburg (Börjesson and Kristoffersson 2015). An air pollution pricing scheme has been implemented in Milan (Rotaris et al 2010). Even though focus and naming are rather driven by political discussions, all pricing schemes have effects on

1 'Externality' refers in this paper to 'negative externality' unless otherwise stated. 
both, congestion and the environment. Percoco (2014) argues that road pricing in Milan has only limited effects on environmental quality and congestion because of an increase in polluting vehicles (motorbikes) and non-polluting vehicles (LPG, bi-fuel and hybrid cars) which are exempted from the toll. Additionally, no significant changes in the flows of prohibited vehicles entering into the city center are observed (Percoco 2015). Similarly, Whitehead et al (2014) investigate the impact of congestion pricing on the demand of new exempted energy efficient vehicles in Stockholm. They show that demand for the exempted energy efficient vehicles increases with a stronger effect on commuters. With a simple example, Nagurney (2000) shows that improvements in travel times may lead to an increase in emissions. Thus, abating congestion and emission can, under certain conditions, turn out to be conflicting goals.

Despite the limited real-world implementations, pricing strategies offer especially in a simulation context - a great opportunity to estimate the magnitude of potential efficiency gains and to identify and avoid possible flaws before implementation. Especially, a thorough investigation of the interrelationship of congestion and air pollution externalities seems promising. In the literature, this potential is only reflected by a relatively small number of contributions: Proost and van Dender (2001) and Chen and Yang (2012) use analytical approaches with static traffic flows; the former considers external effects of congestion, emission, accident and noise for a large-scale scenario of Brussels in Belgium, and the latter obtains Pareto system optimum link flow patterns by simultaneous minimization of travel times and emissions. Wang et al (2014) use a small test network while considering carbon emission costs with generalized cost of travel. To the knowledge of the authors, there exists no contribution attempting a joint internalization of emission and congestion externalities in an agent-based framework with dynamic traffic flows and activity-based demand for a whole metropolitan area.

This paper attempts to close this gap, and to derive general insights from the analysis possibilities of such detailed model. Hence, the present study uses the concept of marginal social cost pricing (Turvey 1963). This concept is used in many previous studies to identify an optimal toll analytically (Vickrey 1969 Arnott et al 1993; Lindsey and Verhoef 2001). However, these simplified approaches are less appropriate for large-scale scenarios with dynamic demand which evolves differently over space and time. The complexity increases in such scenarios and the analytical calculation of such highly differentiated tolls by user behavior in space and time is not feasible. An agent-based simulation framework can bridge this gap: it facilitates to identify the agents who are causing externalities and to charge them with the corresponding price. Thus, an activity-based, multi-agent simulation framework is chosen for this paper because (i) the network loading algorithm is a queue model which controls agents at entry/exit of the link and never in between which makes it computationally faster and therefore suitable for large-scale scenarios, (ii) it provides the dynamic locations of the all agents in the simulation which is required to identify the highly differentiated, time-dependent toll values corresponding to the emission and congestion costs, (iii) the model is embedded 
into an iterative co-evolutionary algorithm, in which agents interact, learn and adapt to the system in general and to the price levels in particular. In a first step, the paper investigates the effect of congestion pricing on emission levels, and the effect of emission pricing on congestion levels. For that purpose, the marginal congestion pricing approach by Kaddoura and Kickhöfer (2014) and the marginal emission pricing approach by Kickhöfer and Nagel (2016) are applied to the a real word scenario of the Munich metropolitan area in Germany. In a second step, the two pricing approaches from above are combined in a joint pricing scheme to investigate the aggregated and disaggregated effects of the correlation between congestion and emission externalities on toll levels and agent behavior. The outcome are optimal congestion-emission levels together with the dynamic, highly differentiated tolls for a particular case study. The methodology that is developed can be applied to any scenario worldwide.

Please note that this paper is builds on a recent study by Agarwal and Kickhöfer (2015). In contrast to that study, the present paper introduces a methodology to identify the amplitude of the correlation between congestion and air pollution externalities. This allows investigating their isolated impact on the overall toll level, e.g. in peak and off-peak hours. The paper also puts more emphasis on relevant policy recommendations by deriving corrected average cost factors per vehicle kilometer for different user groups of the population.

The remainder of the paper is organized as follows: Sec. 2 describes the transport simulation framework which is used for the study, and presents the methodology of internalizing external congestion and emission effects within that framework. Sec. 3 introduces the real-world scenario of the metropolitan area of Munich, Germany, and the different pricing schemes that are considered in the study. Sec. 4 analyses the impacts of the different pricing schemes on agents' behavior and economic indicators, and also performs spatial analyses. Sec. 5 discusses the necessary assumptions of the study and their impact on the overall results. Finally, Sec. 6] concludes the study by summarizing the main findings and by identifying venues for future research.

\section{Methodology}

\subsection{MATSim}

The multi-agent transport simulation MATSim ${ }^{2}$ is used for all simulation runs (see, e.g., Balmer et al 2005, 2009, Raney and Nagel 2004, 2006, for detailed information). MATSim is a framework to simulate transport systems in largescale scenarios. Required inputs are network data, daily plans of individual travelers, and various configuration parameters. Every individual in the simulation framework is considered as an agent who learns and adapts within an iterative process that is composed of three steps as shown in Fig. 1 .

2 'Multi-Agent Transport Simulation', see www.matsim.org 


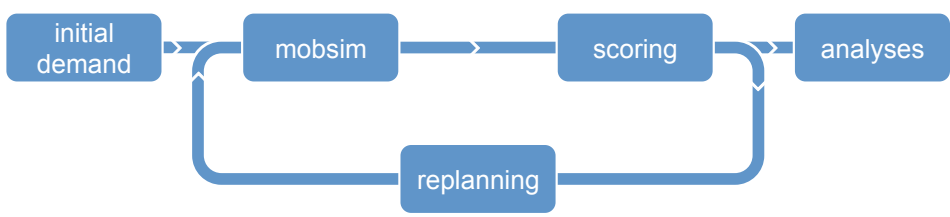

Fig. 1: MATSim cycle (Horni et al in press).

1. Plans Execution (mobsim): All selected plans of agents are executed simultaneously in the physical environment. In this study, a state-of-the-art queuing model (Gawron 1998; Cetin et al 2003) is used.

2. Plans Evaluation (scoring): To compare various plans, executed plans are evaluated using a utility function. A plan's utility $\left(S_{\text {plan }}\right)$ is represented by:

$$
S_{\text {plan }}=\sum_{q=0}^{N-1} S_{a c t, q}+\sum_{q=0}^{N-1} S_{t r a v, \operatorname{mode}(q)}
$$

where $N$ is the number of activities, $S_{a c t, q}$ is the utility from performing activity $q$ and $S_{\text {trav,mode( } q \text { ) }}$ is the (typically negative) utility for traveling to activity $q$. In short, the utility earned for performing an activity is given by ${ }^{3}$

$$
S_{a c t, q}=\beta_{d u r} \cdot t_{t y p, q} \cdot \ln \left(t_{d u r, q} / t_{0, q}\right)
$$

where $t_{d u r, q}$ and $t_{t y p, q}$ are actual and typical durations of activity $q$, respectively. $\beta_{d u r}$ is the marginal utility of activity duration. $t_{0, q}$ is the minimal duration, which essentially has no effect as long as dropping activities is not allowed. The simplified mode-specific utility from traveling by car or public transport (PT) following Nagel et al (in press) is described by:

$$
\begin{array}{r}
S_{\operatorname{car}(q)}=\beta_{\text {trav }, \operatorname{car}(q)} \cdot t_{\text {trav }, q}+\beta_{m} \cdot \gamma_{d, \operatorname{car}(q)} \cdot d_{\text {trav }, q} \\
S_{P T(q)}=C_{P T(q)}+\beta_{\text {trav }, P T(q)} \cdot t_{\text {trav }, q}+\beta_{m} \cdot \gamma_{d, P T(q)} \cdot d_{\text {trav }, q}
\end{array}
$$

where $t_{\text {trav }, q}$ and $d_{\text {trav }, q}$ is the travel time and distance between activity $q$ and $q+1 . C_{p t(q)}$ is the Alternative Specific Constant (ASC) of public transport (PT). As will be illustrated in Sec. 3.2 , the present study defines two different PT modes, and in consequence two PT constants: one for urban travelers and another one for commuters and reverse commuters. All behavioral parameters and the resulting Values of Travel Time Savings (VTTS) are listed in Tab. 1.

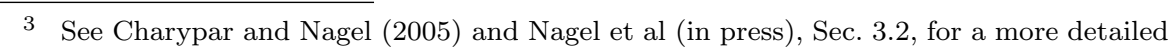
description. 
Table 1: Behavioral parameters.

\begin{tabular}{|c|c|c|}
\hline Parameter & Value & Unit \\
\hline Source: Kickhöfer (2014) & & \\
\hline Marginal utility of activity duration $\left(\beta_{d u r}\right)$ & +0.96 & utils/h \\
\hline Marginal utility of traveling by car $\left(\beta_{\text {trav }, \text { car }}\right)$ & -0.00 & utils/h \\
\hline Marginal utility of traveling by $\mathrm{PT}\left(\beta_{\operatorname{trav}, P T}\right)$ & -0.18 & utils/h \\
\hline Monetary distance rate by car $\left(\gamma_{d, \operatorname{car}(q)}\right)$ & -0.30 & $E U R / k m$ \\
\hline Monetary distance rate by $\mathrm{PT}\left(\gamma_{d, P T(q)}\right)$ & -0.18 & $E U R / k m$ \\
\hline Marginal utility of money $\left(\beta_{m}\right)$ & -0.79 & utils/EUR \\
\hline Approximate average $V T T S_{c a r}$ & +12.15 & $E U R / h$ \\
\hline Approximate average $V T T S_{P T}$ & +14.43 & $E U R / h$ \\
\hline \multicolumn{3}{|c|}{ Calibrated for the present study } \\
\hline ASC for urban PT & -0.75 & utils \\
\hline ASC for (rev.) commuters PT & -0.3 & utils \\
\hline
\end{tabular}

3. Re-planning: For each iteration, a new plan is generated for a predefined share of agents by modifying an existing plan. These modifications are performed by software modules that can be defined arbitrarily. In the present study, route choice and mode choice modules are used.

By repeatedly performing the steps from above, an iterative learning cycle is initiated which finally results in stabilized simulation outputs.

\subsection{Pricing of externalities}

\subsubsection{Congestion cost calculation}

The tool to compute individual delays 4 and then to internalize those by a marginal social cost pricing scheme in the MATSim framework is provided by Kaddoura and Kickhöfer (2014).

This approach tracks routes and travel times of all agents to calculate the time-dependent, agent-specific delay on each link. It is computed whenever an agent is leaving a link. It results from agents who have left that link before the delayed (or affected) agent and who are using capacity and blocking the link. Thus, these downstream agents are named 'causing agents'. In the agent-based framework, causing and affected agents can then be identified. The former can therefore be charged with a monetary equivalent of the sum of marginal delays they have caused to others. The marginal delay is hereby defined as the maximum time for which an agent can block a link. In other words, it is inverse of flow capacity of a link. Since congestion is - in contrast to emissions

\footnotetext{
4 Delay is in this study defined by the difference between the actual travel time on a link and the link's free speed travel time. That is, delays are calculated on a per-link basis and not for entire routes.
} 
Table 2: Emission cost factors. Source: Maibach et al (2008).

\begin{tabular}{lr}
\hline Emission type & Cost factor $($ EUR/ton $)$ \\
\hline $\mathrm{CO}_{2}$ & 70 \\
$\mathrm{NMHC}_{\mathrm{H}}$ & 1,700 \\
$\mathrm{NO}_{x}$ & 9,600 \\
$\mathrm{PM}$ & 384,500 \\
$\mathrm{SO}_{2}$ & 11,000 \\
\hline
\end{tabular}

- inherent to road traffic, the behavioral parameters from Tab. 1 can be used to convert delays into monetary units. This is done using the approximate average Value of Travel Time Savings (VTTS) of the car mode ${ }^{5}$

\subsubsection{Emission cost calculation}

The emission modeling tool was developed by Hülsmann et al (2011) and further improved and extended by Kickhöfer et al (2013). The tool is coupled with the MATSim framework. Currently, emissions are calculated for free flow and stop and go traffic states. Emissions consist of cold emissions (during the warm up phase of vehicle) and warm emissions (while driving); cold emissions essentially depend on parking duration, distance traveled, and vehicle characteristics; warm emissions depend on engine type, road category, and speed of the vehicle. Vehicle characteristics, engine type, road category are taken from the initial inputs whereas travel dynamic attributes (parking duration, distance traveled and speed of the vehicle) are determined from the simulation at the end of each iteration. Thereupon, cold and warm emissions for each agent on each link are calculated using the HBEFA ${ }^{6}$ database.

Furthermore, Kickhöfer and Nagel (2016) developed a method to calculate time-dependent, vehicle-specific emission tolls. In this method, vehicle- and link-specific time-dependent emissions obtained from the emission modeling tool, are converted into monetary units using emission cost factors given in Tab. 2.

\subsubsection{Internalization}

Internalization is the process by which external effects are included into the behavioral decision making of individuals by setting prices according to their

5 The VTTS is defined as the individual willingness-to-pay for reducing the travel time by one hour. For linear utility functions, it is the ratio of the marginal utility of travel time and the marginal utility of money. The former is the sum of the disutility for traveling $\left(\beta_{\text {trav }, \operatorname{mode}(q)}\right)$ and the negative utility of time as a resource $\left(-\beta_{d u r}\right)$. Please note that the person-specific VTTS in MATSim can vary significantly with the time pressure which an individual experiences. This is because of the non-linear utility function for performing activities, influencing the actual value of $\left(\beta_{d u r}\right)$.

6 'Handbook Emission Factors for Road Transport', Version 3.1, see www.hbefa.net 
marginal external costs. By default, the MATSim utility functions only incorporate marginal private costs (MPC) which correspond to spending time and money for traveling to planned activities (see Eq.11 and Eq. 3p. Marginal social costs (MSC) are the sum of MPC and marginal external costs (MEC) (see, e.g., Walters 1961, Turvey 1963). In the present paper, the MEC computed according to Sec. 2.2.1 for congestion and according to Sec. 2.2.2 for emissions are considered in the utility-based learning cycle of MATSim. This is reached by modifying the utility functions - for the internalization scenarios in Tab. 4 - by vehicle-specific, time-dependent tolls $\left(\Delta m_{q}\right)$ as follows:

$$
S_{\operatorname{car}(q)}=\beta_{\text {trav }, \operatorname{car}(q)} \cdot t_{\text {trav }, q}+\beta_{m} \cdot\left(\gamma_{d, \operatorname{car}(q)} \cdot d_{\text {trav }, q}+\Delta m_{q}\right) .
$$

At this point, it is important to note that the individual toll levels change over the iterations, converging to a stable point once the traffic flows stabilize. This is due to the fact that the presented approach is embedded into the iterative co-evolutionary algorithm: In the first iteration, the process starts with charging agents for the delay and the emissions they caused. This is simply the sum of both effects, and on a crowded street segment toll levels are high. As a reaction, some agents opt for other alternatives (mode/route) in the next iteration to improve their overall utilities. This selection between alternatives follows a probability distribution which converges to multinomial logit model (Nagel and Flötteröd 2012). In consequence, toll levels will drop and attract more agents in the subsequent iteration, yielding again higher tolls. That is, over the iterations, the simulation finds a toll level which considers the correlation between the two externalities under consideration without explicitly calculating correction factors.

\subsubsection{Example}

This section provides a small example in order to illustrate the computation of the time-dependent vehicle-specific congestion and emission tolls. Each link in Fig. 2 is $100 \mathrm{~m}$ long and only one agent every $4 s$ is allowed to move to the next link (marginal delay $=4 \mathrm{~s}$ ). Two agents depart at $t=0$ by car and reach the end of the link simultaneously at $t=4,7$

Congestion costs Since the free speed travel time on the link is $5 \mathrm{~s}$, both agents would like to leave the link at $t=5$. However, the flow capacity only allows agent 1 to leave at $t=5$ and then agent 2 to leave at $t=9$. That is, agent 2 has to wait for $4 s$ on the first link with agent 1 being responsible for that delay. Hence, agent 1 will be charged with the monetary equivalent of $4 \mathrm{~s}$, yielding to an individual toll of $4 s \cdot V T T S_{c a r}=1.4$ EURct.

\footnotetext{
7 Please note that, in order to improve the computational efficiency, the queue model controls agents only at link entry/exit and never in between (Agarwal et al 2015). Therefore, both agents can reach at the end of the link simultaneously, however, agents will leave the link while respecting the flow capacity (outflow) of the link.
} 
Emission costs Emissions are calculated for both agents on both links as described in the Sec. 2.2.2. It is assumed in this case that both vehicles have fully cooled down, i.e. experienced a parking duration of minimum $12 h$. Thus on the first link for the first vehicle, parking duration, distance traveled and average speed are $12 h, 100 \mathrm{~m}$ and $20 \mathrm{~m} / \mathrm{s}(=100 \mathrm{~m} / 5 \mathrm{~s})$, respectively. The same calculation for the second vehicle yields $12 \mathrm{~h}, 100 \mathrm{~m}$ and $11.11 \mathrm{~m} / \mathrm{s}(=100 \mathrm{~m} / 9 \mathrm{~s})$. For illustration purpose, the two vehicles are assumed as identical passenger petrol cars with 4-stroke engines. The links are assumed as urban city roads with speed limit of $60 \mathrm{~km} / \mathrm{h}$. Using vehicle characteristics together with this data returns cold and warm emissions from the HBEFA database. These emissions are then converted into monetary units using the emission cost factors in Tab. 2. This yields to an individual toll of 0.9 EURct for cold emissions and 0.12 EURct for warm emissions for the first vehicle on the start link. The same numbers for the second vehicle are 0.9 EURct and 0.14 EURct, respectively.

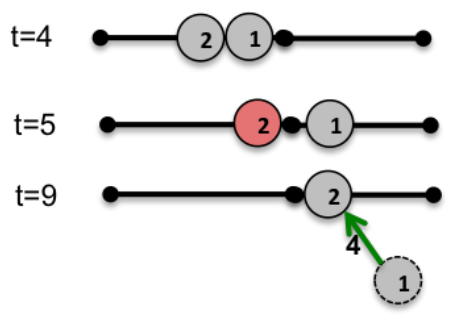

Fig. 2: Example and delay calculation.

\section{Case study : Munich}

This section illustrates the set up of the scenario and the pricing schemes for the real-world case study of the Munich metropolitan area in Germany.

\subsection{Input}

The initial scenario is taken from Kickhöfer and Nagel (2016) and modified for the present study, as will be described in this section.

Network Network data was provided by municipality of Munich (RSB 2005) in the form of VISUM ${ }^{8}$ data. This is converted into a MATSim network, which contains 17,888 nodes and 41,942 links.

8 'Verkehr In Städten UMlegung', see www.ptv.de 
Plans A realistic activity-based demand is created using three different data sources: First, inner urban travel demand was synthesized using detailed survey data based on Mobility in Germany (MiD 2002, Follmer et al 2004). The synthetic demand contains $1,424,520$ individuals with detailed vehicle information. Second, commuters and reverse commuter trips are modeled using data provided by Böhme and Eigenmüller (2006), which contains about 0.5 million individuals, out of these about 0.3 million are commuters and the remaining are reverse commuters. Third, about 0.15 million freight trips are created ( 0.15 million agents with one commercial trip) from data provided by the German Ministry of Transport (ITP and BVU 2007). In the simulation, urban travelers use car, public transport (PT), bike, walk, and ride as transport modes, whereas commuters and reverse commuters use only car or PT. Freight trips are assumed to use only trucks. PT, bike, walk, and ride trips are in the study assumed to run emission free and without capacity constraints. Therefore, there is no emission and congestion externality for such trips, and thus, in the present study, such travel modes are coupled together as noncar travel modes.Overall, for computational performance reasons, $1 \%$ of total population is used for the present study. Agents are categorized among three subpopulations (user groups) namely urban, (reverse) commuters, and freight and therefore, results are discussed based on this classification.

Choice dimensions As a reaction to the policy cases (see Sec. 3.3), new choice sets are generated in the iterative loop of MATSim according to the following rule: In each iteration, $15 \%$ of total agents are allowed to change their route and $15 \%$ of total agents are allowed to change their travel mode from car to PT or from PT to car 9 The rest of the agents chose a plan from their existing choice set according to a multinomial logit model. After $80 \%$ of the iterations, the choice set is fixed and agents can only chose from existing alternatives. In case of freight, mode choice is not available, i.e. all freight trips use car mode only.

\subsection{Base case}

A base case is set up by running simulation for 1000 iterations. The base case in the present study is similar to the base case from Kickhöfer and Nagel (2016). However, that study calibrated the ASC for PT assuming a uniform PT speed of $25 \mathrm{~km} / \mathrm{h}$ for all user groups while matching the modal split for urban travelers. As a consequence, the modal split for commuters and reverse commuter did not match the reference study (see Tab. 3. "Common PT speed (it.1000)").

Therefore, in the present study, PT speed $(25 \mathrm{~km} / \mathrm{h})$ for urban travelers is kept, and for commuters and reverse commuters, it is assumed to be

\footnotetext{
$9 \quad$ An urban traveler can switch mode between car and slower PT (speed $25 \mathrm{~km} / \mathrm{h}$ ) and similarly, commuters and reverse commuters can switch mode between car and faster PT (speed $50 \mathrm{~km} / \mathrm{h}$ ). See Sec. 3.2 for details on slower and faster PT.
} 
$50 \mathrm{~km} / \mathrm{h}$, emulating faster trains between the city center and suburbs. In consequence, the base case is re-calibrated, eventually resulting in an ASC of -0.3 for (rev.) commuters. Tab. 3. "Different PT speed (it.1000)", shows the results of this calibration effort. The combined modal split of commuters and reverse commuters is now very close to the initial plans and the reference study. Because of the decrease in car share for commuters and reverse commuters, there is some relief of capacities on the network. In consequence, the share of car trips for urban travelers increases from $20.11 \%$ to $21.20 \%$ which is also closer to the reference study.

Table 3: Modal split from reference studies, initial demand and calibrated base cases.

\begin{tabular}{|c|c|c|c|c|}
\hline & \multicolumn{2}{|c|}{ Urban } & \multicolumn{2}{|c|}{ (Rev.) commuters } \\
\hline & car & non-car & car & non-car \\
\hline Reference study ${ }^{10}$ & 26.00 & 74.00 & 67.00 & 33.00 \\
\hline Initial demand (it.0) & 22.48 & 77.52 & 67.97 & 32.03 \\
\hline Common PT speed (it.1000) & 20.11 & 79.89 & 96.59 & 3.41 \\
\hline Different PT speed (it.1000) & 21.20 & 78.80 & 66.62 & 33.38 \\
\hline
\end{tabular}

\subsection{Policy cases}

After the calibration of the base case, the simulation is further continued for 500 iterations along with the 'Business As Usual' (BAU) case and three pricing schemes (see Tab. 4). The output of the base case after iteration 1000 is used as inputs for all four policy cases. As described in Sec. 2.2.3, different user-specific external costs are internalized for the scenarios listed in Tab. 4 The final iterations (1500) of the pricing schemes are compared with the final iteration of BAU. Emission costs, congestion costs and toll payments for all four scenarios are computed as follows:

1. Emissions costs: Time-dependent and person-specific cold and warm emissions are calculated as described in Sec. 2.2.2. These emissions are then transformed into monetary units using emission costs factors (see Tab. 2). These monetary emissions costs are summed up to get total emission costs in each scenario.

2. Congestion costs: As illustrated in Sec. 2.2.1. disaggregated delays are calculated on a per-link basis for each causing agent and then converted into monetary units using the approximate average VTTS. Afterwards, these values are summed up to get the total congestion costs for each scenario.

\footnotetext{
10 Follmer et al (2004) for urban travelers and MVV (2007) for commuters and reverse commuters.
} 
3. System welfare: In order to perform economic evaluation for all three pricing scenarios, travel related user benefits are calculated by converting the utility of each agent into monetary terms ${ }^{11}$. Congestion costs and the negative perception of toll payments are both implicitly part of user benefits. Toll payments are, however, simply transfer payments from users to public authorities. Consequently, the change in system welfare is defined as the sum of changes in emission costs, toll payments, and user benefits.

Table 4: Policy cases.

\begin{tabular}{lll}
\hline Policy case & Externality & Internalization \\
\hline Business As Usual (BAU) & none & none \\
Emissions Internalization $(\mathrm{EI})$ & emissions & see Sec. 2.2.2 \\
Congestion Internalization $(\mathrm{Cl})$ & congestion & see Sec. 2.2.1 \\
Emissions and Congestion Internalization $(\mathrm{ECl})$ & both & both \\
\hline
\end{tabular}

\section{Results}

In this section, the levels of the external costs are illustrated (Sec. 4.1) and subsequently, the effects of the pricing schemes on system performance is presented (Sec.4.2). Furthermore, Sec. 4.3 and Sec. 4.4 provide more detailed and disaggregated analyses for different agent groups. The emphasis will thereby be put on the driving forces behind the increase in system performance, and on the isolated impacts of each externality on the overall toll level. All figures in the presentation of the results are for a typical working day and scaled to the full population. The idea behind the comparison of the pricing schemes is (i) to investigate the influence of internalizing one externality on the other externality, and (ii) to test whether the correlation between the two externalities in the combined internalization (ECI) has policy implications.

\subsection{BAU: amplitude of externalities}

For the Munich metropolitan area, congestion costs amount to approximately $7.3 \mathrm{~m}$ EUR which is about twice as high as the emission costs $(3.7 \mathrm{~m}$ EUR). This is in line with estimates from the literature, where congestion cost estimates

\footnotetext{
11 The user benefits calculated from the utility of the last executed plan are not same as the user benefits calculated from the logsum over all plans of an agent. The latter (also sometimes called expected maximum utility) considers utility from heterogeneity in the choice set and is in theory the preferable figure for calculating user benefits in MATSim (see Kickhöfer and Nagel in press). However, as the authors point out, the current MATSim implementation might, under certain conditions, yield biased choice sets. In consequence, the utility of the last executed plan is used in the present paper for economic analysis.
} 
are typically higher than emission cost estimates (see, e.g., Maibach et al 2008 Parry and Small 2005).

Fig. 3 shows for the BAU scenario and each user group the share of agents and external costs. The caused emission costs of a user group are total costs of emissions produced by all vehicles of that group. Freight car trips consists of only about $8 \%(0.15 \mathrm{~m})$ of all car trips, but is responsible for more than $65 \%$ $(2.5 \mathrm{~m} \mathrm{EUR})$ of emission costs. This is due to the fact that freight vehicles (i) emit more emissions than other vehicles and, (ii) have longer travel distances (mean and median trip distances are $111 \mathrm{~km}$ and $69 \mathrm{~km}$, respectively).

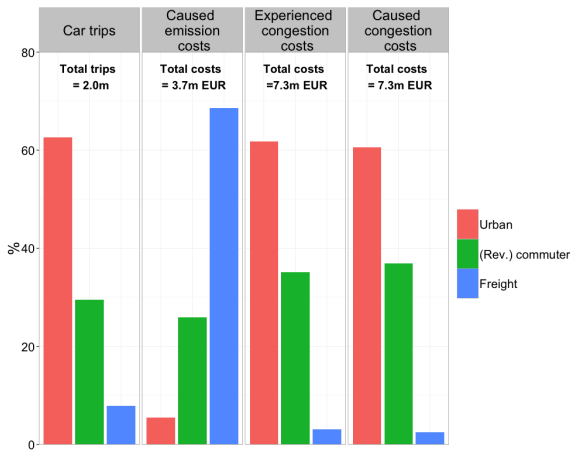

Fig. 3: Share of car trips, emission and congestion costs for different user groups for BAU scenario.

Congestion costs are classified into two categories, namely 'experienced congestion costs' and 'caused congestion costs' ${ }^{12}$ The former are costs experienced, the latter are costs caused by the respective group. Thus, experienced congestion costs are also influenced by agents from other user groups. The share of car trips for urban travelers is more than $60 \%$ (1.3m car trips) of the total car trips. They experience and cause about 4.5 and $4.4 \mathrm{~m}$ EUR of the congestion costs, respectively. This is expected since they perform most of the trips and congestion is predominant in urban areas. Together with freight, they are causing less congestion (i.e. delays) than they experience. On the contrary, (rev.) commuters cause $(2.7 \mathrm{~m} E U R)$ more than what they experience $(2.6 \mathrm{~m}$ $E U R)$. In the congestion pricing regimes of this paper, agents are charged for the delays they cause to others and therefore caused congestion costs will be referred to as congestion costs in the remainder of the paper.

12 A recent study by Kickhöfer and Kern 2015) shows that the framework in principle allows for a similar classification in the case of emission costs. However, in the present study, only caused emission costs are considered and referred to as 'emission costs' from here on. 
Table 5: Key indicators for all pricing schemes in million EUR per typical working day.

\begin{tabular}{l|rrr}
\hline \multirow{2}{*}{ Benefits from ... } & \multicolumn{3}{|c}{ Pricing scheme } \\
\cline { 2 - 4 } & EI & CI & ECI \\
\hline ... changes in emission costs (1) & 0.10 & 0.17 & 0.27 \\
... changes in congestion costs (2) & 0.91 & 3.61 & 3.96 \\
Changes in travel related user benefits (3) & -2.75 & 0.44 & -2.34 \\
Toll revenues (4) & 3.61 & 3.68 & 6.78 \\
\hline \hline Changes in system welfare $(=1+3+4)$ & 0.96 & 4.27 & 4.71 \\
\hline
\end{tabular}

\subsection{Pricing: system performance}

Absolute changes in external costs, toll payments, user benefits and system welfare as a result of the three different pricing schemes are shown in Tab. 5 . The reduction in emission costs for EI, CI and ECI pricing schemes are $2.72 \%$, $4.49 \%$, and $7.22 \%(0.10 \mathrm{~m}, 0.17 \mathrm{~m}$, and $0.27 \mathrm{~m} \mathrm{EUR})$, respectively. These values follow the same trend as in the previous work (Agarwal and Kickhöfer 2015) who found reductions in emission costs of $0.57 \%, 1.94 \%$ and $2.48 \%$ for the same pricing schemes. However, that study did not account for different PT speeds (see Sec. 3.2), which seems to have an important effect on the price elasticity of car travel demand. The decrease in emission costs is for all pricing schemes more significant in the present paper which indicates that capturing the elasticities accurately has a major impact on the results. The reduction in congestion costs for EI, CI and ECI pricing schemes are $12.70 \%, 49.66 \%$, and $54.44 \%(0.91 \mathrm{~m}, 3.61 \mathrm{~m}$, and $3.96 \mathrm{~m}$ EUR), respectively.

Hence, internalizing emissions (EI) results in approx. $0.91 \mathrm{~m} E U R$ less congestion costs. Internalizing congestion (CI) results in approx. $0.17 \mathrm{~m} E U R$ less emission costs. Thus, pricing one externality has a positive impact on the other externality. That is, the externalities prove to be positively correlated. The positive correlation is also found in a study by Beevers and Carslaw (2005), who show that the London congestion charging scheme reduced $N O_{x}$ and $P M_{10}$ by $12 \%$ and $11.9 \%$ respectively between 2002 and 2003 . The combined pricing scheme (ECI) exhibits the highest reductions in emission costs $(0.27 \mathrm{~m} \mathrm{EUR})$ and congestion costs $(3.96 \mathrm{~m} \mathrm{EUR})$, and the highest gain in system welfare $(4.71 \mathrm{~m}$ EUR). That is, the combined pricing scheme improves system performance the most. An interesting observation can be made for the changes in 'travel related user benefits': they are negative for EI and ECI and positive for CI. This stems from the fact that, for CI, the reduction in travel times overcompensates the loss from toll payments yielding a positive change in user benefits. For EI and ECI, the reduction in travel times is smaller than the loss from toll payments yielding a negative change in user benefits.

To summarize, the following observations are obtained: (1) pricing congestion (CI) results in a decrease of emissions; (2) pricing emissions (EI) yields a reduction in congestion; (3) the lowest levels of external costs are observed 
in the combined pricing scheme (ECI); (4) system welfare is highest for ECI. These findings are confirmed for all user groups under investigation. However, when looking at the effects differentiated by user groups, some interesting additional observations can be made. In particular:

1. Pricing emissions (EI) diverts freight trips on shorter ( $\Delta$ average distance $=-0.2 \mathrm{~km}$ ) but more congested links and consequently a slight increase in congestion costs is observed. That is, pricing emissions might yield higher congestion levels (also see later in Sec. 4.4). This effect is known from a study by (Yin and Lawphongpanich 2006), where authors experimented on a 6 node test network and found that emission internalization may sometimes produce less emissions but higher delays.

2. All three pricing schemes yield a decrease in user benefits for all user groups except for urban travelers. For them, the gain in utility from the reduction in travel times is higher than the loss because of toll payments which eventually produces higher user welfare. When pricing congestion (CI), this gain overcompensates the losses of the other user groups and finally results in increased user benefits for the whole population (see Tab. 5).

For now, the point with the most important policy implication, however, is the following: The sum of toll revenues from the isolated pricing schemes is roughly $7.29 \mathrm{~m}$ EUR whereas the total toll revenues for combined pricing is roughly $6.78 \mathrm{~m} \mathrm{EUR}{ }^{13}$ The lessons learned here are that simply combining the average toll levels from the isolated pricing schemes (EI and CI) for policy making will result in over-pricing. This is due to the correlation between congestion and air pollution externalities. The same is likely to be true for a policy which combines marginal cost factors from the literature, since there are typically no cost estimates for emissions given an existing congestion pricing scheme or cost estimates for congestion given an existing emission pricing scheme.

\subsection{Pricing: driving forces}

The increase in system performance indicators is a combined effect of users' reactions with respect to two choice dimensions, mode choice and route choice (see Sec. 3.1). This section aims at presenting the driving forces behind the increases in system performance by performing a more in-depth analysis.

Modal split Tab. 6 shows the impact of the pricing schemes on modal split. For the EI case, the share of car trips decreases for (rev.) commuters whereas it increases slightly for urban travelers. Because of the higher average toll per trip for (rev.) commuters (see Tab. 7), a significant number of car users in

\footnotetext{
13 This result has been confirmed by two simulations with different random seeds, which are used to initialize the pseudo random number generator in MATSim . A different random seed will eventually result in different simulation outcomes. For an example of the effect of randomness on optimal supply in MATSim, see, e.g., Kaddoura et al (2015).
} 
this user group switches to PT. This reliefs some capacity and leads to an increase in the car share of urban travelers. In contrast, for the CI and ECI case, car share decreases for both user groups. This is because the average toll per trip for urban travelers is by a factor of 12 higher than in EI. This effect is less pronounced for (rev.) commuters, however, also their toll increases by a factor of 1.5 and 2.5 from the EI to the CI and ECI case, respectively. On the aggregated level, one observes - as expected - that the higher the toll, the more agents switch from car to PT, depending on the implicit price elasticity of demand. This elasticity is dependent on the availability of substitutes, i.e. if agents are not able to switch mode because of insufficient alternatives, pricing can not be used to increase the system efficiency. Daniel and Bekka (2000) have found in their models that potential welfare gains decrease with a decrease in the elasticity of demand. The results in the present paper support this finding. On the disaggregated level, however, the agent-based simulation framework exhibits the complex structure of human interactions in transport decisions. Because of capacity relief, pricing car emissions might increase the car share for certain agents. Similarly, increasing the toll level (i.e. going from CI to ECI) might decrease the reduction in car share for certain agents.

Table 6: Changes in car share (\% points) with respect to BAU for all pricing schemes.

\begin{tabular}{l|rrr}
\hline & Urban & (Rev.) commuters & Freight \\
\hline $\mathrm{EI}$ & +0.22 & -7.04 & 0.00 \\
$\mathrm{CI}$ & -0.66 & -16.25 & 0.00 \\
$\mathrm{ECI}$ & -0.48 & -23.46 & 0.00 \\
\hline
\end{tabular}

Table 7: Average toll payments (EUR) per car trip for all pricing schemes.

\begin{tabular}{l|rrr}
\hline & Urban & (Rev.) commuters & Freight \\
\hline $\mathrm{EI}$ & 0.16 & 1.62 & 16.04 \\
$\mathrm{CI}$ & 1.96 & 2.46 & 0.92 \\
$\mathrm{ECI}$ & 2.00 & 4.12 & 16.96 \\
\hline
\end{tabular}

Travel time Fig. 4 shows the change in average trip travel time for mode switchers and retainers. One observes that the average trip travel time decreases significantly for agents who retain car as transport mode, as well as for agents who change from PT to car: the toll in the car mode improves car travel times, so car gets attractive in particular for short trips. In contrast, travel time is increased for the agents who switch from car to PT. These agents are better off by shifting to the time-consuming PT travel mode than paying toll. 
Interestingly, with the CI pricing scheme, agents who stay in the car mode are shifting to less congested but longer routes (see Fig. $7 \mathrm{c}$ ) in order to dampen their toll. In contrast, agents who switch from PT to car prefer to pay toll which is compensated by significant reductions in travel time.

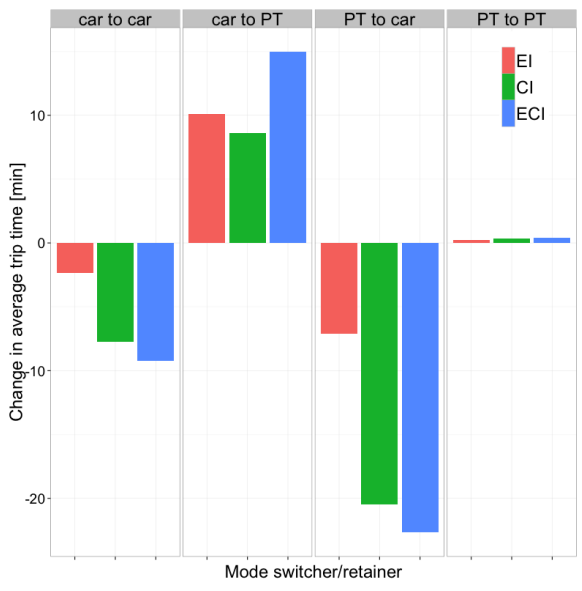

Fig. 4: Changes in average trip travel time for mode switchers and retainers.

Table 8: Average toll levels (EURct/ $\mathrm{km}$ ) in the car mode for peak and off-peak hours.

\begin{tabular}{l|l|rrr}
\hline Time & Pricing scheme & Urban & (Rev.) commuters & Freight \\
\hline Peak & El & 2.61 & 2.24 & 14.45 \\
& $\mathrm{Cl}$ & 36.38 & 3.62 & 1.28 \\
& $\mathrm{ECl}$ & 37.83 & 5.40 & 15.70 \\
\hline Off-peak & $\mathrm{El}$ & 2.56 & 2.19 & 14.45 \\
& $\mathrm{Cl}$ & 29.99 & 2.70 & 0.63 \\
& $\mathrm{ECl}$ & 30.46 & 4.59 & 15.08 \\
\hline
\end{tabular}

Peak/off-peak tolls Tab. 8 shows the average toll levels in the car mode for peak ${ }^{14}$ and off-peak hours, now in EURct $/ \mathrm{km}$. The resulting average toll levels are plausible values: e.g. Parry and Small (2005) use local pollution costs for automobile of 1.18 EURct/ $\mathrm{km}$ for US and UK, and external congestion costs as 2.06 and $4.11 \mathrm{EURct} / \mathrm{km}$ for US and UK respectively. Clearly, due to higher

14 Peak hours are identified as 07:00-10:00 and 15:00-18:00 considering total travel demand of all user groups in the BAU scenario. 
Table 9: Contributions of externalities to the ECI toll levels $(E U R c t / k m)$ in the car mode in peak and off-peak hours.

\begin{tabular}{l|l|rrr}
\hline Time & Externality & Urban & (Rev.) commuters & Freight \\
\hline Peak & Emissions & $2.51(6.6 \%)$ & $2.22(41.1 \%)$ & $14.44(92.0 \%)$ \\
& Congestion & $35.32(93.4 \%)$ & $3.18(58.9 \%)$ & $1.26(8.0 \%)$ \\
\hline \multirow{2}{*}{ Off-peak } & Emissions & $2.49(8.2 \%)$ & $2.18(47.5 \%)$ & $14.43(95.7 \%)$ \\
& Congestion & $27.97(91.8 \%)$ & $2.41(52.5 \%)$ & $0.65(4.3 \%)$ \\
\hline
\end{tabular}

generated emissions, toll values for freight trips are very high. Similarly, higher congestion from urban travelers yields higher toll values.

Peak-hour toll levels are - as expected - higher than off-peak tolls. For CI and ECI, urban travelers exhibit a six to ten times higher toll level per vehicle kilometer than (rev.) commuters whereas for EI, this factor is about 1.2 only. This was not yet visible from the tolls per trip in Tab. 7. Freight tolls are almost not influenced by congestion pricing since the emission toll dominates the overall price level.

Tab. 9 shows the contributions of the two externalities to the overall ECI toll level for peak and off-peak hours. The first important finding is that the contribution of emissions to the overall toll level is higher in off-peak than in peak hours. This is valid for all user groups. In comparison with Tab. 8 , the figures in Tab. 9 additionally exhibit that, in the EI case, emissions are more strongly overpriced in peak hours than in off-peak hours. To give an example: in EI, peak hour emission prices for urban travelers are $4.0 \%((2.61-2.51) / 2.51)$ higher than in the ECI case. In off-peak hours, this price difference only amounts to $2.8 \%$. In contrast, in the CI case, peak hour congestion prices for urban travelers are only $3.0 \%((36.38-35.32) / 35.32)$ higher than in the ECI case. In off-peak hours, this price difference increases to $7.2 \%$. That is, for a combined pricing scheme, cost estimates from the literature need to be reduced because of the correlation between air pollution and congestion externalities. For the emission estimates, these reductions should be stronger in peak hours. For the congestion estimates, these reductions should be stronger in off-peak hours. Alternatively, the joint internalization model as is proposed in the present paper can help to determine the joint amplitude of the externalities and help to design pricing schemes of any desired complexity, ranging from little price differentiations to highly personalized tolls. For illustration purposes, Fig. 5 shows the toll payments for all three pricing schemes and all subpopulations in one hour time bins. It emphasizes the importance of the interrelation of emission and congestion externalities and their variation over time of day and user groups. 


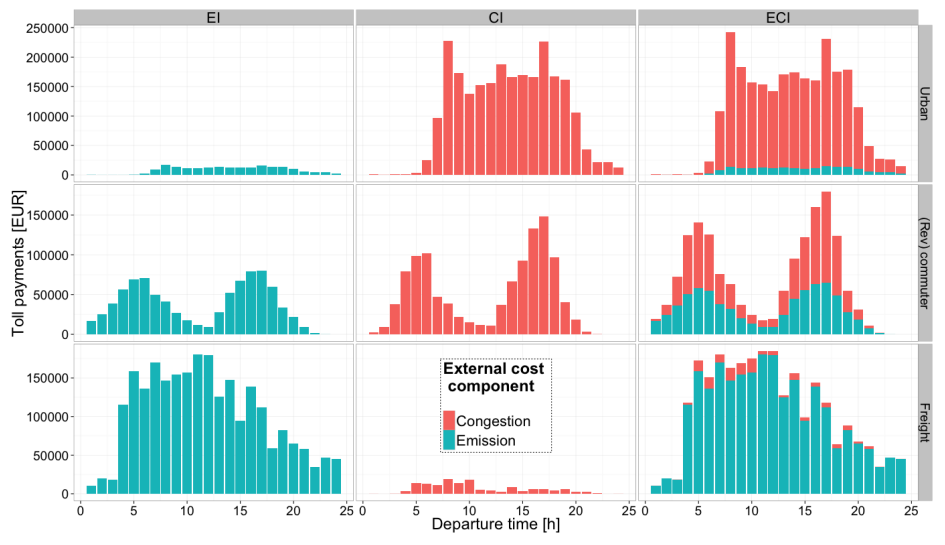

Fig. 5: Toll payments over time of day for all pricing schemes and subpopulations in EUR. Values are scaled to full population.

\subsection{Pricing: spatial distribution}

The impact of the three pricing schemes on a spatially disaggregated level is presented in this section.

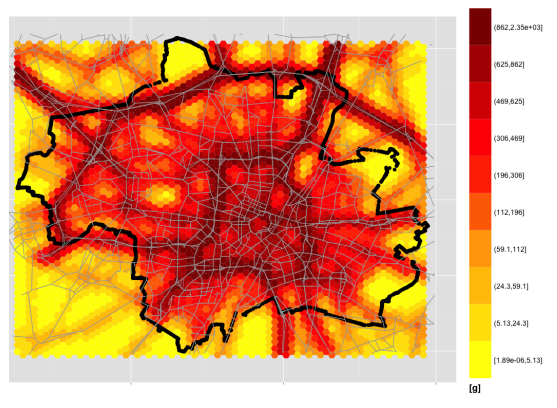

(a) Absolute $\mathrm{NO}_{2}$ emission

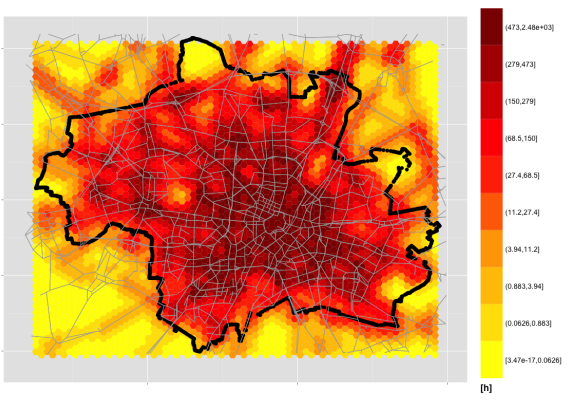

(b) Absolute delay

Fig. 6: Absolute emissions (in $[\mathrm{g}]$ ) and delays (in [h]). Values are scaled to full population.

The spatial dimension of external costs in the BAU scenario is shown in Fig. $6{ }^{15}$ Time-dependent and person-specific link-based emissions and delays

\footnotetext{
15 For the visual presentation, a Gaussian distance weighting function is used to smooth emissions and delays throughout the area of Munich and surroundings. Uniform hexagonal cells of size $500 \mathrm{~m}$ are used for this purpose. The smoothing radius is assumed to be $500 \mathrm{~m}$. For more information on the exact visualization procedure, please refer to Kickhöfer (2014).
} 
are presented. Fig. 6a shows absolute $\mathrm{NO}_{2}$ emissions ${ }^{16}$ and Fig. $6 \mathrm{~b}$ shows absolute delays. It can be observed that emissions are most important on primary roads (inner and middle ring road, main arterials, and the tangential motorway in the north-west of Munich). In contrast, congestion is evident on almost all roads inside the city area, but not as important on the tangential motorway.

Fig. 7 shows the changes in $\mathrm{NO}_{2}$ emissions and in delay for the off-peak hours (i.e. 00:00-07:00, 10:00-15:00 and 18:00-24:00) ${ }^{17}$ An increase in emissions or delays is represented by red color, a decrease by green color. The spatial plots on the left show the change in $\mathrm{NO}_{2}$ whereas the plots on the right show the change in delays with respect to the BAU scenario. For the EI case, Fig. $7 \mathrm{a}$ and $7 \mathrm{~b}$ show that agents are re-routing towards shorter distance routes. This is indicated by an increase of emissions and delays in the inner city. As a consequence, $\mathrm{NO}_{2}$ emissions are decreased in particular on the north-west tangential motorway and other long-distance routes, basically wherever $\mathrm{NO}_{2}$ emission was high in the BAU. For the CI case, Fig. $7 \mathrm{c}$ and $7 \mathrm{~d}$ show that agents re-route from congested links to non-congested and longer distance routes. Thus, $\mathrm{NO}_{2}$ emissions and delays are decreased significantly inside the central areas of Munich. On the contrary, $\mathrm{NO}_{2}$ emissions are increased on parts of the tangential motorway where $\mathrm{NO}_{2}$ emissions were already high in the BAU scenario. The effect of combined pricing on a spatial level is shown in Fig. 7e and 7f] Since congestion costs dominate emission costs, the patterns in ECI are similar to those from CI. However, the combined pricing yields a decrease in $\mathrm{NO}_{2}$ emissions and delays in most areas of the city.

The lessons learned here are that - for congested regimes - the two pricing schemes (EI and CI) affect the route choice behavior of agents by tendency into opposite directions: EI towards shorter distance routes, increasing congestion; CI towards longer distance routes, increasing emissions.

\section{Discussion}

The goal of this paper is to present a simulation-based approach to calculate and internalize the correct dynamic price levels for congestion and emission externalities simultaneously. For a large-scale real-world case study, it is shown that this iterative calculation of prices allows to identify the amplitude of the correlation between these two externalities without explicitly calculating correction factors. The approach combines activity-based demand with dynamic traffic flow simulations. Behavioral reactions to time-dependent vehicle-specific congestion and/or emission tolls are modeled for every agent of the system. Clearly, given this complexity of the approach, several assumptions and simplifications are made. In the following, it is discussed to what extent these

\footnotetext{
16 All important pollutants are considered for pricing. For illustration purposes, the emission plot only shows $\mathrm{NO}_{2}$.

17 In peak hours, the congestion pricing scheme and combined pricing scheme exhibit similar patterns.
} 


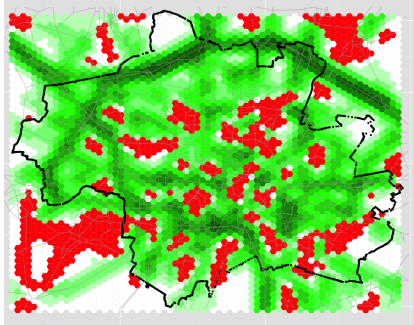

(a) Change in $\mathrm{NO}_{2}$ levels for EI

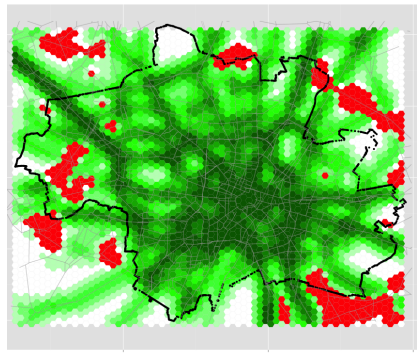

(c) Change in $\mathrm{NO}_{2}$ levels for CI

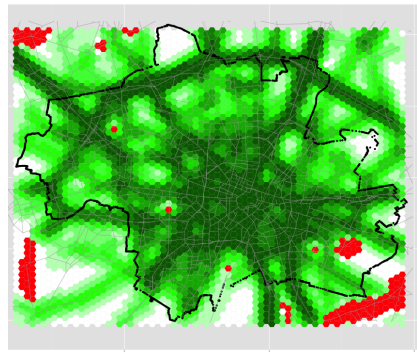

(e) Change in $\mathrm{NO}_{2}$ levels for ECI

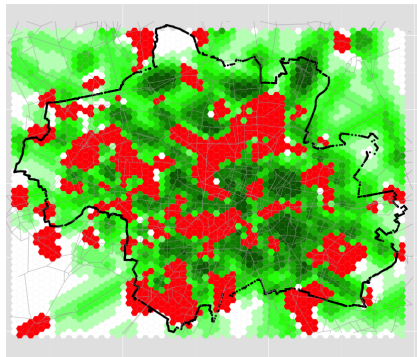

(b) Change in delay for EI

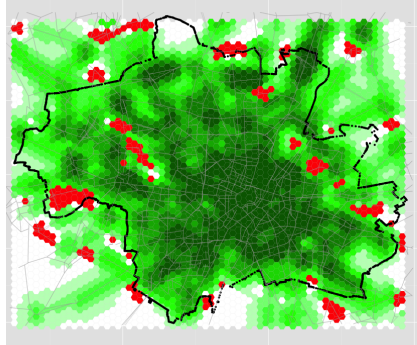

(d) Change in delay for CI

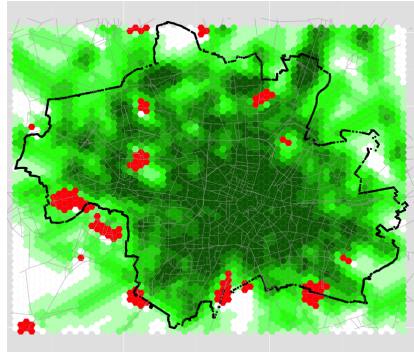

(f) Chmm in delay for ECI $0.353,307$

$(-0.000307,0.353]$

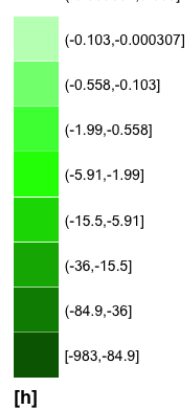

[h] [g]

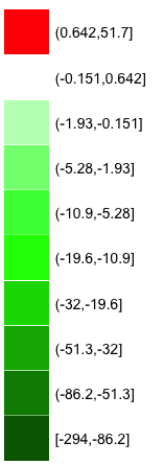

Fig. 7: Changes in $\mathrm{NO}_{2}$ emissions (in [g]) and delays (in[h]) for all pricing schemes in the off-peak hours. Values are scaled to full population. 
assumptions and simplifications might influence the results structurally and how the they can be used for deriving or evaluating policy interventions.

Commercial traffic The full behavioral modeling of commercial vehicles is beyond the scope of the present study (see Schröder et al 2012: Zilske et al 2012 for some ongoing work to integrate this in the model). However, to not simply ignore congestion and environmental effects of the commercial vehicles, they are simulated as freight user group in the scenario along with the other user groups. With respect to congestion, other vehicles can delay a truck and a truck can delay other vehicles. In that sense, congestion effects are accounted for. The only assumption here is that one truck uses as much road capacity as one car. That is, the congestion toll for trucks is underestimated. This should be tackled in the future by modifying the queue model in such way that it accounts for passenger car equivalents (see Agarwal et al 2015, 2016, for some ongoing work in this context). With respect to emissions, vehicle and engine type are assumed to be identical for all trucks. There is no differentiation by type of commercial vehicle. However, if data is available, the approach in principle allows for this differentiation according to the HBEFA database. That is, the emission toll is as accurate as the underlying demand data allows. In absence of a separate behavioral model for commercial vehicles, the VTTS for trucks is assumed to be identical to the VTTS of car users, which is certainly lower than the typical values from the literature. Hence, the vehicles will by tendency choose routes with too short distances and too long travel times in comparison to reality. However, as they are only allowed to change their route (other user groups can additionally switch mode), the effect of this simplification on the overall results is expected to be small.

Choice dimensions In this study, agents are only allowed to change their route and/or their mode of transport. Incorporating other choice dimensions such as departure time or location choice will certainly have an impact on the results. For instance, the potential efficiency gains depend on the implicit price elasticities of car travel demand. More options by tendency increase the demand elasticities and with it the potential efficiency gains. That is, the figures presented in this papers are rather at the lower bound of the potential impacts induced by pricing congestion and/or emission externalities.

Improved scenario setup In the present study, the scenario setup is improved by introducing a faster public transit for (reverse) commuters which is a more viable option to commute between the city center and suburbs. Consequently, the decrease in the emission costs under different pricing schemes is more significant in the present study than in the previous study by Agarwal and Kickhöfer (2015). Hence, an improved scenario setup yields more realistic elasticities and is important for estimating the potential welfare gains from pricing schemes. 
Policy implications The individual tolls in this paper are obtained by using the idea of marginal social cost pricing in an agent-based context. Even though the resulting highly differentiated tolls are difficult to implement and it additionally is unclear if users would actually understand the ever-changing price signals correctly, marginal social cost pricing still lays the foundation to derive toll values for reality. The time-dependent vehicle-specific tolls obtained by the presented approach can be aggregated or averaged in many ways, and it is part of future research to find good pricing schemes which obtain most of the benefits but still remain feasible to implement, always depending on the scenario and the requirements of the case. One option for transferring the insights from marginal cost pricing into recommendations for policy makers are the back-calculated tolls presented in the paper (corrected average toll levels per kilometer). They exhibit, for the case study under consideration, the interrelationship between the external cost components and how their respective contribution to the overall effect changes over time of day. Apart from deriving the correct price levels for policy making, the welfare maximizing system state can be used as a benchmark to evaluate other policies such as traffic calming measures (speed humps/bumps, speed limit restrictions; Buehler and Pucher 2011; Ghafghazi and Hatzopoulou 2014), parking policies (Wall 2011; Attard and Ison 2015 ) and traffic control measures (Li et al 2004: Osorio and Nanduri 2015) with respect to various indicators. This seems a promising road for future applications of the proposed approach.

\section{Conclusion}

This study investigates separate marginal social cost pricing strategies for congestion and emission externalities in a real-world case study of the Munich metropolitan area. The two pricing strategies are then combined to obtain a simulation-based approach to calculate and internalize the correct dynamic price levels for both externalities simultaneously. Since the underlying multiagent simulation framework is computational efficient, the presented approach is - in contrast to analytical models - suitable for the calculation of highly differentiated tolls in large-scale simulations with dynamic traffic flows and activity-based demand.

As expected, the results indicate that the two externalities are positively correlated. It is demonstrated that the combined pricing yields the lowest level of emission and congestion externalities for whole the population as well as for individual user groups. It also yields the highest level of system welfare. The main driving force behind this overall effect is found to be modal shift from car towards public transit. Interestingly, this effect is present on the aggregated level but it was also found that external cost pricing can increase the car share of urban travelers who profit from a capacity relief which results from the reduction in car share of other travelers.

Furthermore, it was found that simply combining the average toll levels obtained from the isolated pricing schemes or from uncorrected exogenous 
cost estimates will result in overpricing. The amplitude of this effect was shown to be more important in peak hours for emissions and in off-peak hours for congestion. Policy makers should, hence, account for the correlations between different externalities and correct the cost estimates. As the main contribution of this paper it was shown that the joint internalization approach makes it possible to identify the amplitude of this correlation between the externalities under consideration. The methodology is then used to derive corrected average toll levels per vehicle kilometer. An aggregation according to any other desired simplification rule seems feasible, which offers opportunities for policy design.

Finally, the spatial distribution of changes in the externalities was analyzed. It was shown that pricing emissions steers agents on shorter distance routes and pricing congestion pushes agents on shorter travel times routes with potentially longer distance routes. Thus, for congested areas, route choice behavior of agents is by tendency affected into opposite direction by the two pricing schemes. This needs to be accounted for when designing real-world policies: An emission (or distance)-based toll might increase congestion whereas a congestion-based toll might increase emissions. Therefore, the presented model seems necessary to simultaneously account for both externalities. In future research, the model is planned to be integrated with agent-based pricing schemes of other relevant externalities such as emission exposure (Kickhöfer and Kern 2015), noise exposure (Kaddoura et al 2016) and accidents.

Acknowledgements Part of the material from a preliminary version of the work has been presented at the $14^{\text {th }}$ International Conference on Travel Behavior Research (IATBR) 2015 in Windsor, London. Important data was provided by the Municipality of Munich, more precisely by Kreisverwaltungsreferat München and Referat für Stadtplanung und Bauordnung München. The support given by DAAD (German Academic Exchange Service) to Amit Agarwal for his PhD studies at Technische Universität Berlin is greatly acknowledged. The authors also wish to thank Kai Nagel (Technische Univsersität Berlin) for his helpful comments and H. Schwandt and N. Paschedag at the Department of Mathematics (Technische Universität Berlin), for maintaining our computing clusters. Finally, the authors are grateful to three anonymous reviewers for their valuable comments. The responsibility of any remaining errors stays with the authors.

\section{References}

Agarwal A, Kickhöfer B (2015) Agent-based simultaneous optimization of congestion and air pollution: A real-world case study. Procedia Computer Science 52(C):914-919, DOI 10.1016/j.procs.2015.05.165

Agarwal A, Zilske M, Rao K, Nagel K (2015) An elegant and computationally efficient approach for heterogeneous traffic modelling using agent based simulation. Procedia Computer Science 52(C):962-967, DOI 10.1016/j.procs.2015.05.173

Agarwal A, Lämmel G, Nagel K (2016) Modelling of backward travelling holes in mixed traffic conditions. In: Knoop VL, Daamen W (eds) Traffic and Granular Flow '15, Springer International Publishing, Delft, NL, DOI 10.1007/978-3-319-33482-0_53

Arnott R, de Palma A, Lindsey R (1993) Properties of dynamic traffic equilibrium involving bottlenecks, including a paradox and metering. Transportation Science 27(2):148-160, DOI $10.1287 / \operatorname{trsc} .27 .2 .148$ 
Attard M, Ison S (2015) The effects of road user charges in the context of weak parking policies: The case of Malta. Case Studies on Transport Policy 3(1):37-43, DOI http: //dx.doi.org/10.1016/j.cstp.2014.07.001, urban Transport Policy

Balmer M, Raney B, Nagel K (2005) Adjustment of activity timing and duration in an agent-based traffic flow simulation. In: Timmermans H (ed) Progress in activity-based analysis, Elsevier, Oxford, UK, pp 91-114

Balmer M, Rieser M, Meister K, Charypar D, Lefebvre N, Nagel K, Axhausen K (2009) MATSim-T: Architecture and simulation times. In: Bazzan A, Klügl F (eds) MultiAgent Systems for Traffic and Transportation, IGI Global, pp 57-78

Beevers SD, Carslaw DC (2005) The impact of congestion charging on vehicle emissions in London. Atmospheric Environment 39:1-5, DOI 10.1016/j.atmosenv.2004.10.001

Böhme S, Eigenmüller L (2006) Pendlerbericht Bayern. Tech. rep., IAB

Börjesson M, Kristoffersson I (2015) The Gothenburg congestion charge. effects, design and politics. Transportation Research Part A: Policy and Practice 75:134-146, DOI 10.1016/j.tra.2015.03.011

Buehler R, Pucher J (2011) Sustainable transport in Freiburg: lessons from Germany's environmental capital. International Journal of Sustainable Transportation 5(1):43-70, DOI 10.1080/15568311003650531

Cetin N, Burri A, Nagel K (2003) A large-scale agent-based traffic microsimulation based on queue model. In: Swiss Transport Research Conference (STRC), Monte Verita, Switzerland, URL http://www.strc.ch see http://www.strc.ch

Charypar D, Nagel K (2005) Generating complete all-day activity plans with genetic algorithms. Transportation 32(4):369-397, DOI 10.1007/s11116-004-8287-y

Chen L, Yang H (2012) Managing congestion and emissions in road networks with tolls and rebates. Transportation Research Part B: Methodological 46:933-948, DOI 10.1016/j. trb.2012.03.001

Creutzig F, He D (2009) Climate change mitigation and co-benefits of feasible transport demand policies in Beijing. Transportation Research Part D: Transport and Environment 14(2):120-131, DOI 10.1016/j.trd.2008.11.007

Daniel JI, Bekka K (2000) The environmental impact of highway congestion pricing. Journal of Urban Economics 47:180-215, DOI 10.1006/juec.1999.2135

Eliasson J, Hultkrantz L, Nerhagen L, Rosqvist LS (2009) The Stockholm congestion charging trial 2006: Overview of effects. Transportation Research Part A: Policy and Practice 43:240-250, DOI 10.1016/j.tra.2008.09.007

van Essen H, Schroten A, Otten M, Sutter D, Schreyer C Zandonella R, Maibach M, Doll C (2011) External costs of transport in Europe. Tech. rep., CE Delft

Follmer R, Kunert U, Kloas J, Kuhfeld H (2004) Mobilität in Deutschland - Ergebnisbericht. Tech. rep., infas/DIW, Bonn, URL www.kontiv2002.de

Gawron C (1998) Simulation-based traffic assignment. PhD thesis, University of Cologne, Cologne, Germany

Ghafghazi G, Hatzopoulou M (2014) Simulating the environmental effects of isolated and area-wide traffic calming schemes using traffic simulation and microscopic emission modeling. Transportation 41:633-649

Horni A, Nagel K, Axhausen KW (in press) Introducing MATSim. In: Horni A, Axhausen KW, Nagel K (eds) The Multi-Agent Transport Simulation MATSim, Ubiquity, London, chap 1, URL http://matsim.org/the-book

Hülsmann F, Gerike R, Kickhöfer B, Nagel K, Luz R (2011) Towards a multi-agent based modeling approach for air pollutants in urban regions. In: Conference on "Luftqualität an Straßen", Bundesanstalt für Straßenwesen, FGSV Verlag GmbH, pp 144-166, also VSP WP 10-15, see http://www.vsp.tu-berlin.de/publications

ITP, BVU (2007) Prognose der deutschlandweiten Verkehrsverflechtungen 2025. Tech. rep., Intraplan Consult GmbH, Beratergruppe Verkehr+Umwelt GmbH, URL http://daten. clearingstelle-verkehr.de/220/

Kaddoura I, Kickhöfer B (2014) Optimal road pricing: Towards an agent-based marginal social cost approach. VSP Working Paper 14-01, TU Berlin, Transport Systems Planning and Transport Telematics, see http://www.vsp.tu-berlin.de/publications

Kaddoura I, Kickhöfer B, Neumann A, Tirachini A (2015) Agent-based optimisation of public transport supply and pricing: Impacts of activity scheduling decisions and simulation 
randomness. Transportation 42(6):1039-1061, DOI 10.1007/s11116-014-9533-6

Kaddoura I, Kröger L, Nagel K (2016) User-specific and dynamic internalization of road traffic noise exposures. Networks and Spatial Economics DOI 10.1007/s11067-016-9321-2

Kickhöfer B (2014) Economic policy appraisal and heterogeneous users. PhD thesis, TU Berlin, Berlin

Kickhöfer B, Kern J (2015) Pricing local emission exposure of road traffic: An agent-based approach. Transportation Research Part D: Transport and Environment 37(1):14-28, DOI 10.1016/j.trd.2015.04.019

Kickhöfer B, Nagel K (2016) Towards high-resolution first-best air pollution tolls. Networks and Spatial Economics 16(1):175-198, DOI 10.1007/s11067-013-9204-8

Kickhöfer B, Nagel K (in press) Microeconomic interpretation of MATSim for benefit-cost analysis. In: Horni A, Axhausen KW, Nagel K (eds) The Multi-Agent Transport Simulation MATSim, Ubiquity, London, chap 51, URL http://matsim.org/the-book

Kickhöfer B, Hülsmann F, Gerike R, Nagel K (2013) Rising car user costs: comparing aggregated and geo-spatial impacts on travel demand and air pollutant emissions. In: Vanoutrive T, Verhetsel A (eds) Smart Transport Networks: Decision Making, Sustainability and Market structure, NECTAR Series on Transportation and Communications Networks Research, Edward Elgar Publishing Ltd, pp 180-207

Li X, Li G, Pang SS, Yang X, Tian J (2004) Signal timing of intersections using integrated optimization of traffic quality, emissions and fuel consumption: a note. Transportation Research Part D: Transport and Environment 9(5):401-407, DOI 10.1016/j.trd.2004.05. 001

Lindsey R, Verhoef ET (2001) Traffic congestion and congestion pricing. In: Hensher D, Button K (eds) Handbook of Transport Systems and Traffic Control, Handbooks in Transport, vol 3, pp 77-105

Maibach M, Schreyer D, Sutter D, van Essen H, Boon B, Smokers R, Schroten A, Doll C, Pawlowska B, Bak M (2008) Handbook on estimation of external costs in the transport sector. Tech. rep., CE Delft, URL http://ec.europa.eu/transport/sustainable/doc/ 2008_costs_handbook.pdf Internalisation Measures and Policies for All external Cost of Transport (IMPACT)

MVV (2007) Regionaler Nahverkehrsplan für das Gebiet des Münchner Verkehrs- und Tarifverbundes. Tech. rep., Munich Local Transport Provider

Nagel K, Flötteröd G (2012) Agent-based traffic assignment: Going from trips to behavioural travelers. In: Pendyala R, Bhat C (eds) Travel Behaviour Research in an Evolving World - Selected papers from the 12th international conference on travel behaviour research, International Association for Travel Behaviour Research, chap 12, pp 261-294

Nagel K, Kickhöfer B, Horni A, Charypar D (in press) A closer look at scoring. In: Horni A, Axhausen KW, Nagel K (eds) The Multi-Agent Transport Simulation MATSim, Ubiquity, London, chap 3, URL http://matsim.org/the-book

Nagurney A (2000) Congested urban transportation networks and emission paradoxes. Transportation Research Part D: Transport and Environment 5(2):145-151, DOI 10.1016/S1361-9209(99)00031-0

Osorio C, Nanduri K (2015) Urban trasportation emission mitigation: coupling highresolution vehicular emissions and traffic models for traffic signal optimization. Transportation Research Part B: Methodological 81(2):520-538, DOI 10.1016/j.trb.2014.12. 007

Parry I, Small K (2005) Does Britain or the United States have the right gasoline tax? The American Economic Review 95(4):1276-1289, DOI 10.1257/0002828054825510

Percoco M (2014) The effect of road pricing on traffic composition: Evidence from a natural experiment in Milan, Italy. Transport Policy 31(0):55-60, DOI 10.1016/j.tranpol.2013. 12.001

Percoco M (2015) Heterogeneity in the reaction of traffic flows to road pricing: a synthetic control approach applied to milan. Transportation 42(6):1063-1079, DOI 10.1007/ s11116-014-9544-3

Pigou A (1920) The Economics of Welfare. MacMillan, New York

Proost S, van Dender K (2001) The welfare impacts of alternative policies to address atmospheric pollution in urban road transport. Regional Science and Urban Economics 31(4):383-411, DOI 10.1016/S0166-0462(00)00079-X 
Raney B, Nagel K (2004) Iterative route planning for large-scale modular transportation simulations. Future Generation Computer Systems 20(7):1101-1118, DOI 10.1016/j.future. 2003.11.001

Raney B, Nagel K (2006) An improved framework for large-scale multi-agent simulations of travel behaviour. In: Rietveld P, Jourquin B, Westin K (eds) Towards better performing European Transportation Systems, Routledge, London, pp 305-347

Rotaris L, Danielis R, Marcucci E, Massiani J (2010) The urban road pricing scheme to curb pollution in Milan, Italy: Description, impacts and preliminary cost-benefit analysis assessment. Transportation Research Part A: Policy and Practice 44(5):359-375, DOI 10.1016/j.tra.2010.03.008

RSB (2005) Municipality of Munich: Referat für Stadtplanung und Bauordnung

Schröder S, Zilske M, Liedtke G, Nagel K (2012) A computational framework for a multi-agent simulation of freight transport activities. Annual Meeting Preprint 124152, Transportation Research Board, Washington D.C., also VSP WP 11-19, see http://www.vsp.tu-berlin.de/publications

Turvey R (1963) On divergences between social and private cost. Economica 30(119):309313, DOI 10.2307/2601550

Vickrey W (1969) Congestion theory and transport investment. The American Economic Review 59(2):251-260

Wall G (2011) Environmental parking charging policies: a case study of Winchester. Local Economy 26(4):246-259, DOI 10.1177/0269094211404624

Walters AA (1961) The theory and measurement of private and social costs of highway congestion. Econometrica 29(4):676-699, DOI 10.2307/1911814

Wang J, Chi L, Hu X, Zhou H (2014) Urban traffic congestion pricing model with the consideration of carbon emissions cost. Sustainability 6(2):676-691, DOI 10.3390/su6020676

Weinreich S, Rennings K, Schlomann B, Geßner C, Engel T (1998) External costs of road, rail and air transport - A bottom-up approach. ZEW Discussion Papers 98-06

Whitehead J, Franklin JP, Washington S (2014) The impact of a congestion pricing exemption on the demand for new energy efficient vehicles in Stockholm. Transportation Research Part A: Policy and Practice 70:24-40, DOI 10.1016/j.tra.2014.09.013

Yin Y, Lawphongpanich S (2006) Internalizing emission externality on road networks. Transportation Research Part D: Transport and Environment 11:292-301, DOI 10.1016/j. sbspro.2014.07.198

Zilske M, Schröder S, Nagel K, Liedtke G (2012) Adding freight traffic to MATSim. VSP Working Paper 12-02, TU Berlin, Transport Systems Planning and Transport Telematics, see http://www.vsp.tu-berlin.de/publications 